Supplementary Information for

\title{
Quantifying stratospheric biases and identifying their potential sources in subseasonal forecast systems
}

Zachary D. Lawrence, Marta Abalos, Blanca Ayarzagüena, David Barriopedro, Amy H. Butler, Natalia Calvo, Alvaro de la Cámara, Andrew Charlton-Perez, Daniela I.V. Domeisen, Etienne Dunn-Sigouin, Javier García-Serrano, Chaim I. Garfinkel, Neil P. Hindley, Liwei Jia, Martin Jucker, Alexey Y. Karpechko, Hera Kim, Andrea L. Lang, Simon H. Lee, Pu Lin, Marisol Osman, Froila M. Palmeiro, Judith Perlwitz, Inna Polichtchouk, Jadwiga H. Richter, Chen Schwartz, Seok-Woo Son, Irina Statnaia, Masakazu Taguchi, Nicholas L. Tyrrell, Corwin J. Wright, and Rachel W.-Y. Wu 


\section{$\mathrm{BoM}^{*}$}
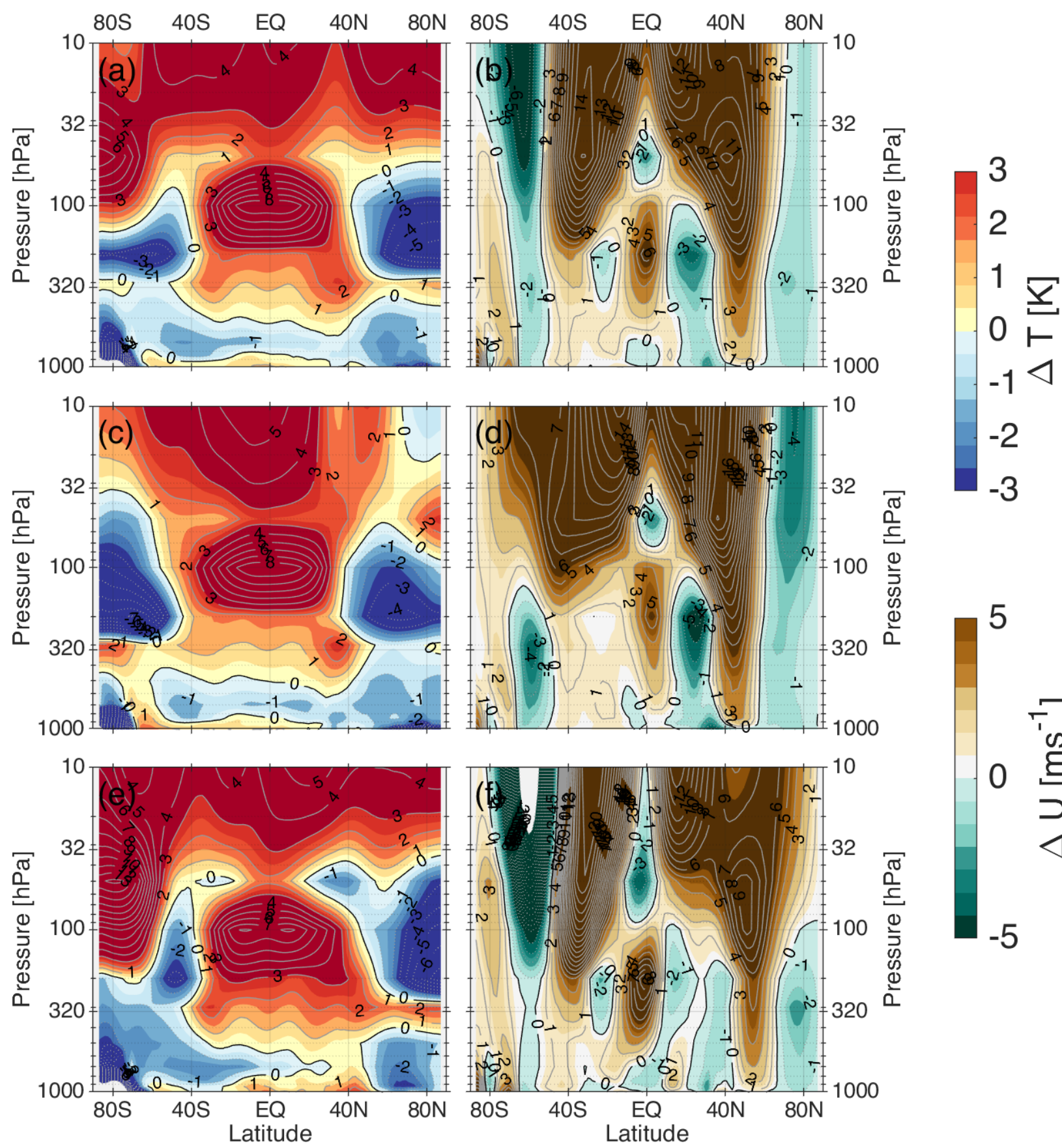

Figure S1. The week-4 zonal mean biases computed from the BoM hindcasts for (left column) temperatures and (right column) zonal winds. The top row represents the annual mean biases, while the middle and bottom rows are for DJF and JJA, respectively. 


\section{CESM2-CAM*}
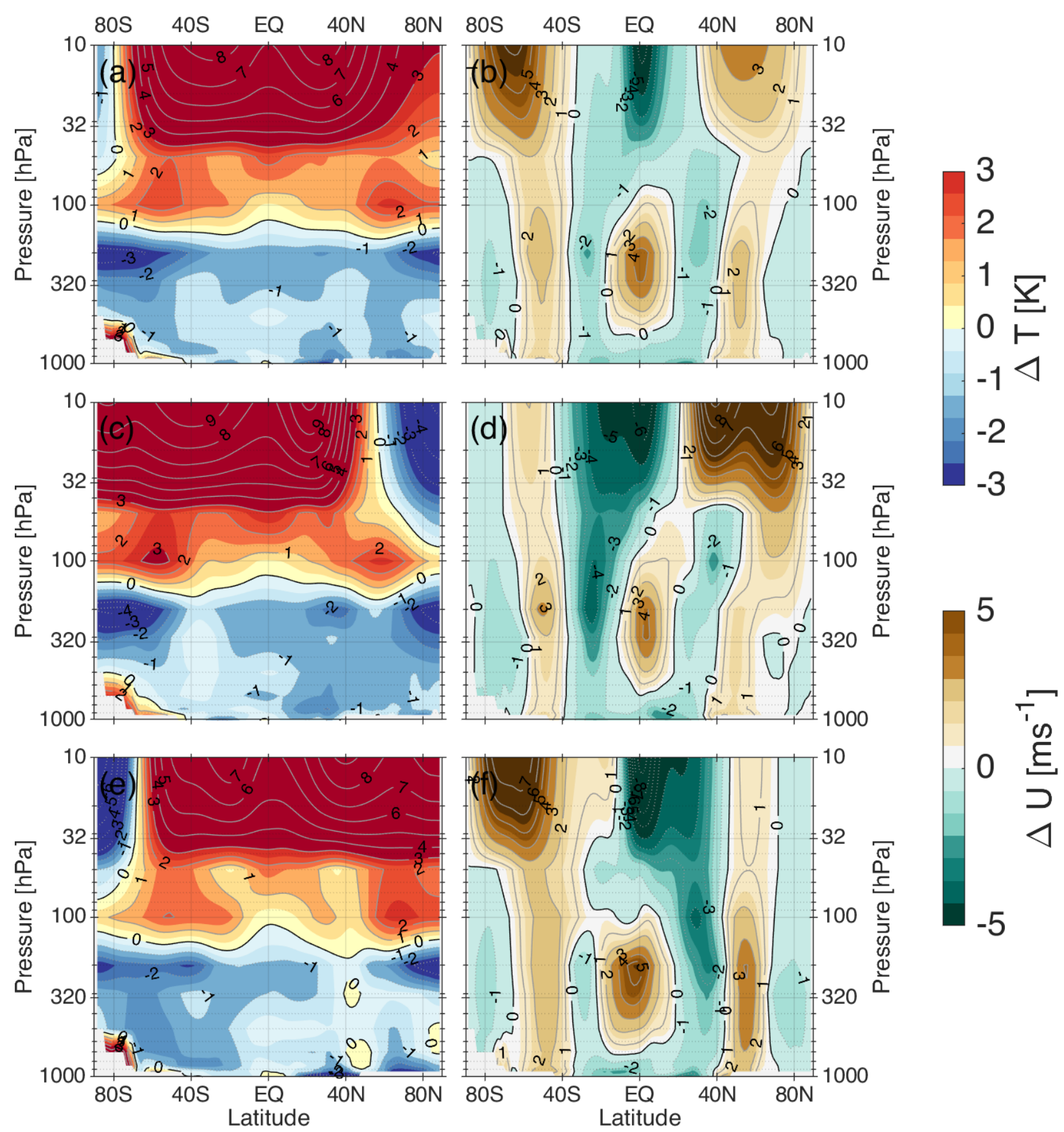

Figure S2. As in Figure S1, but for the CESM2-CAM system. 


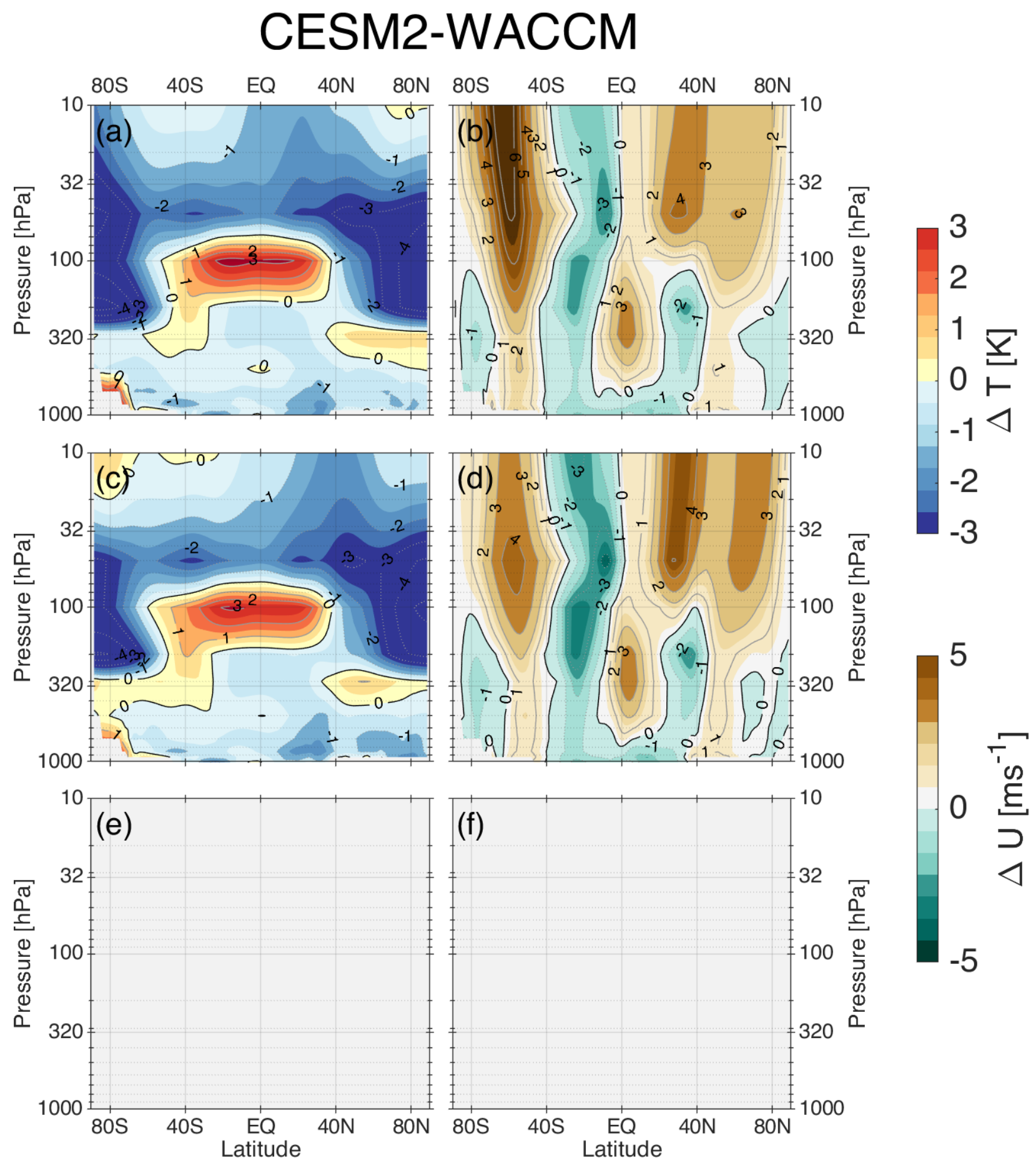

Figure S3. As in Figure S1, but for the CESM2-WACCM system. The bottom row is left blank since the CESM2-WACCM system only ran hindcasts from September to March. The "annual-mean" composite in the top row is then based only on 7 months (excluding April-August). 


\section{CMA-S2Sv1*}
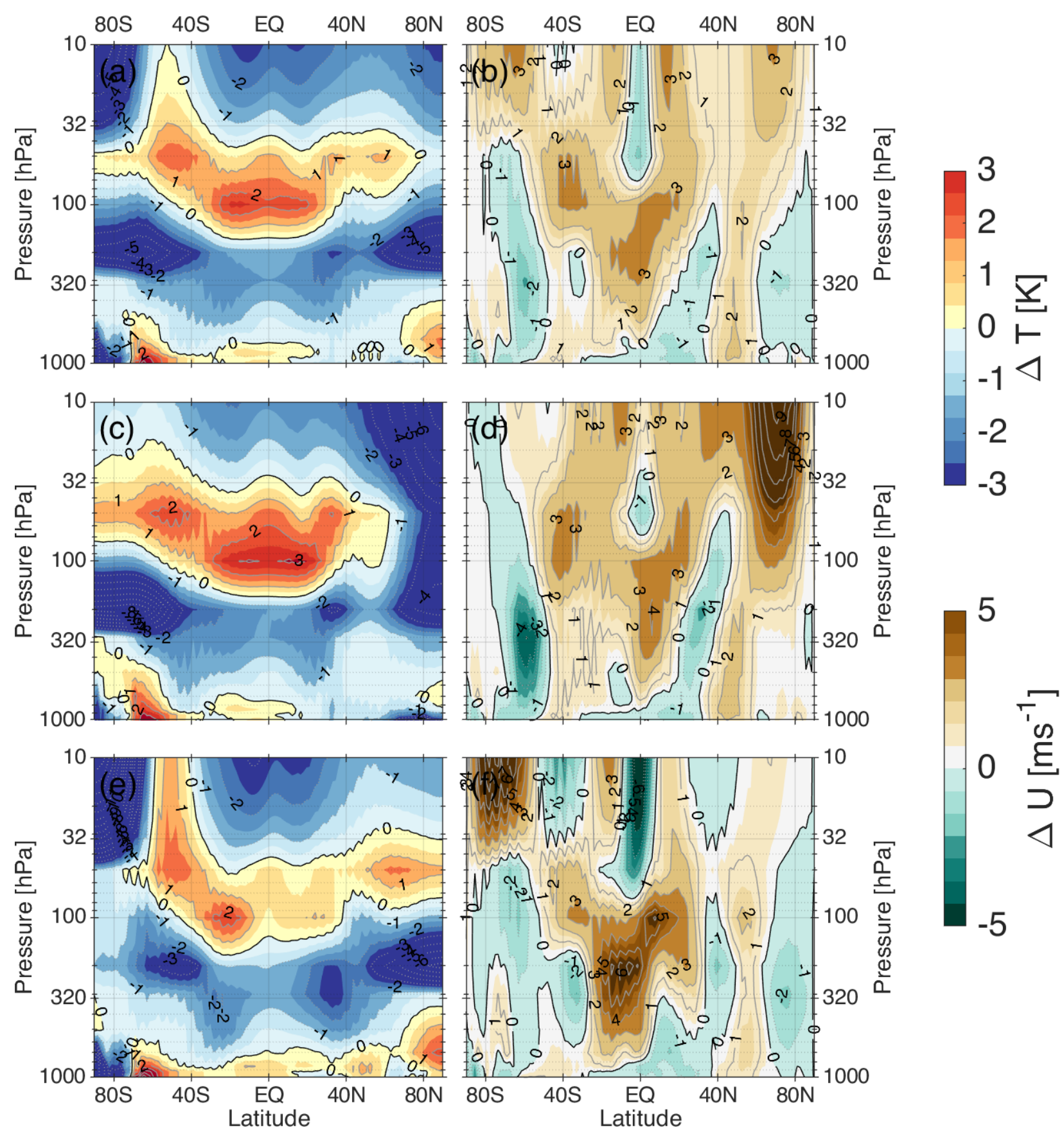

Figure S4. As in Figure S1, but for the CMA system. 


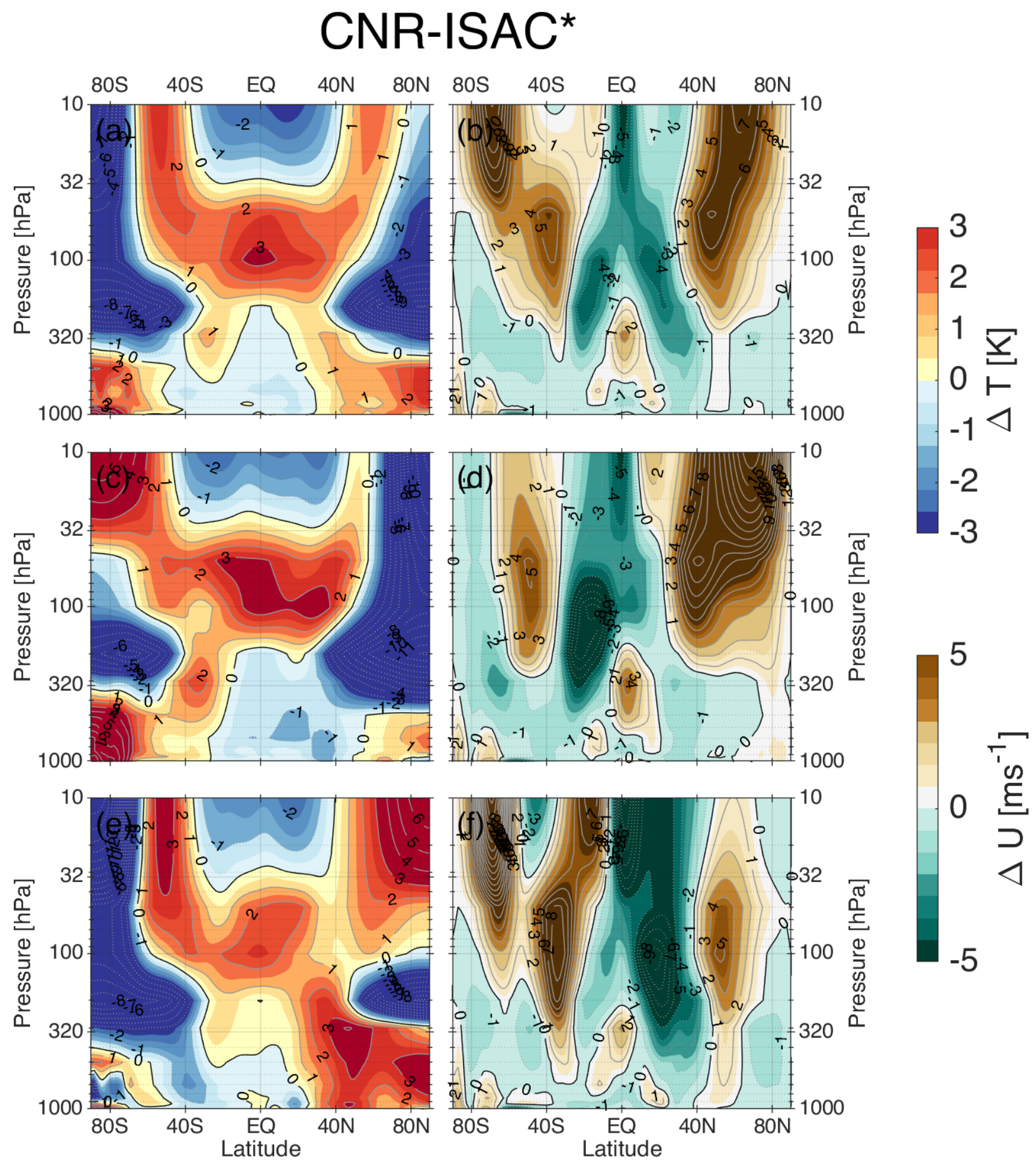

Figure S5. As in Figure S1, but for the CNR-ISAC system. 


\section{CNRM}
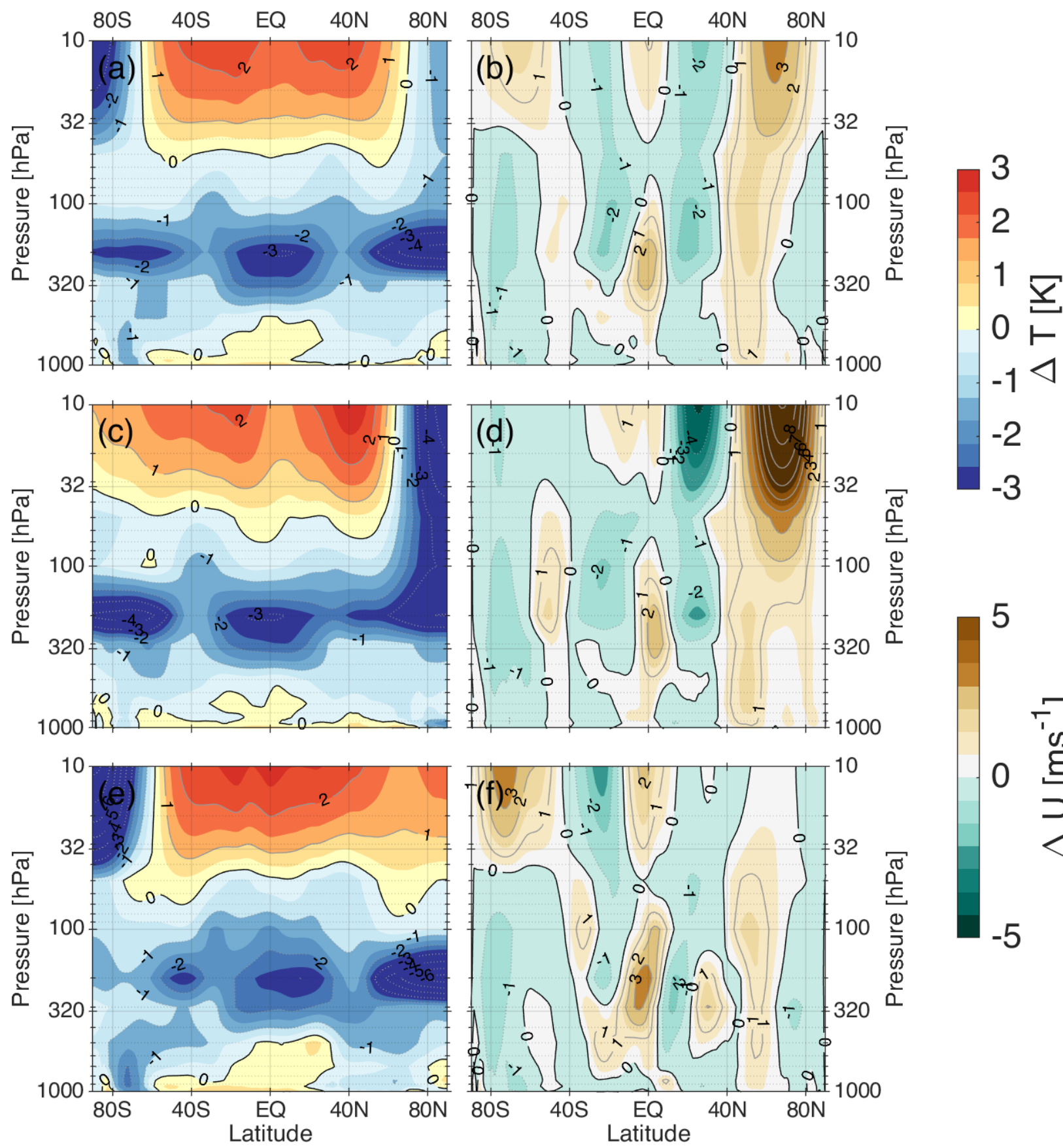

Figure S6. As in Figure S1, but for the CNRM system. 


\section{ECCC-GEM16*}
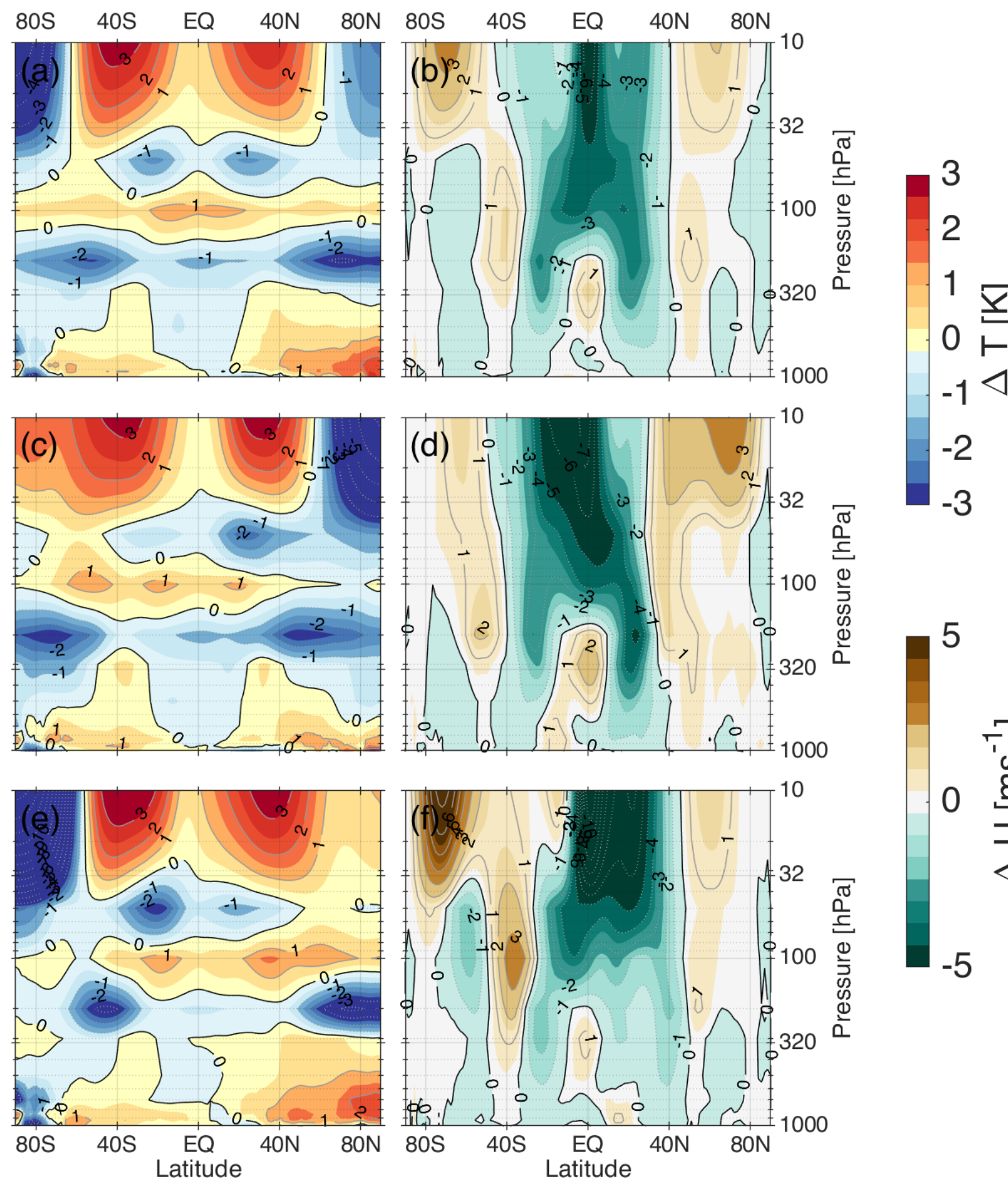

$-2$

$-3$

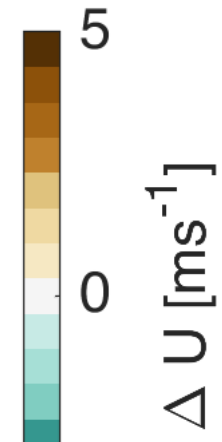

Figure S7. As in Figure S1, but for the low-top ECCC system (GEM16). 


\section{ECCC-GEPS19}
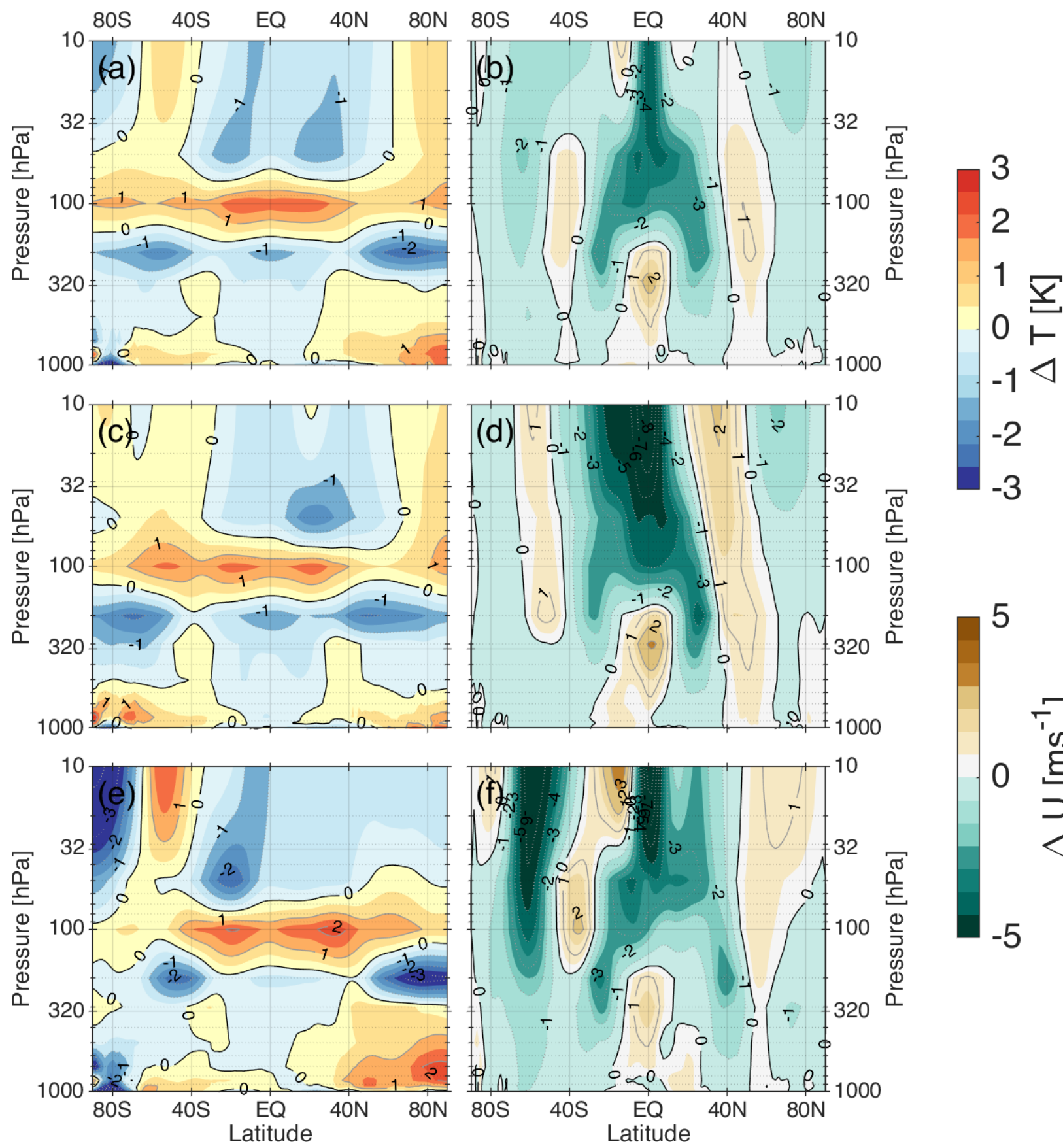

Figure S8. As in Figure S1, but for the high-top ECCC system (GEPS19). 


\section{ECMWF}
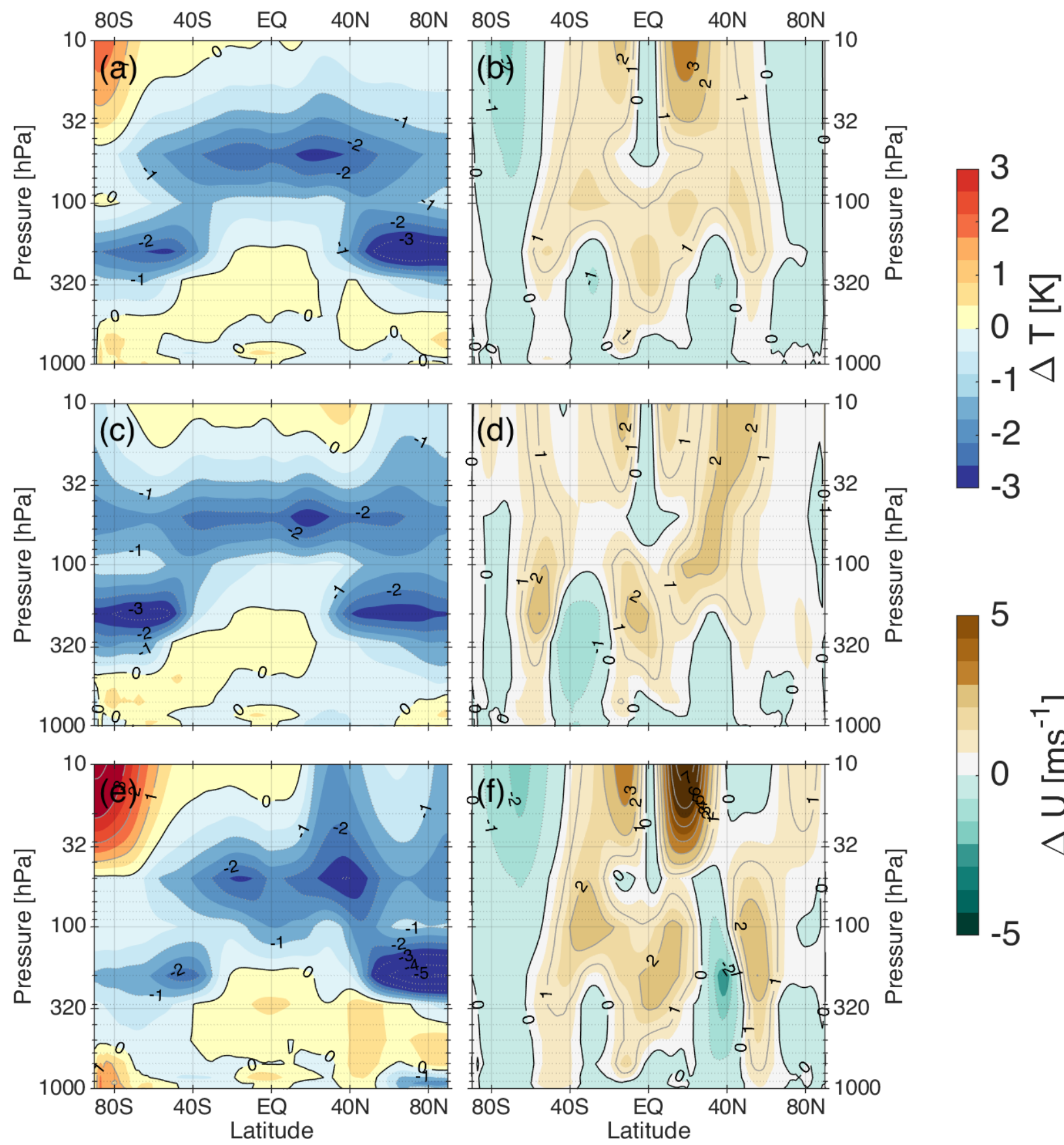

Figure S9. As in Figure S1, but for the ECMWF system. 


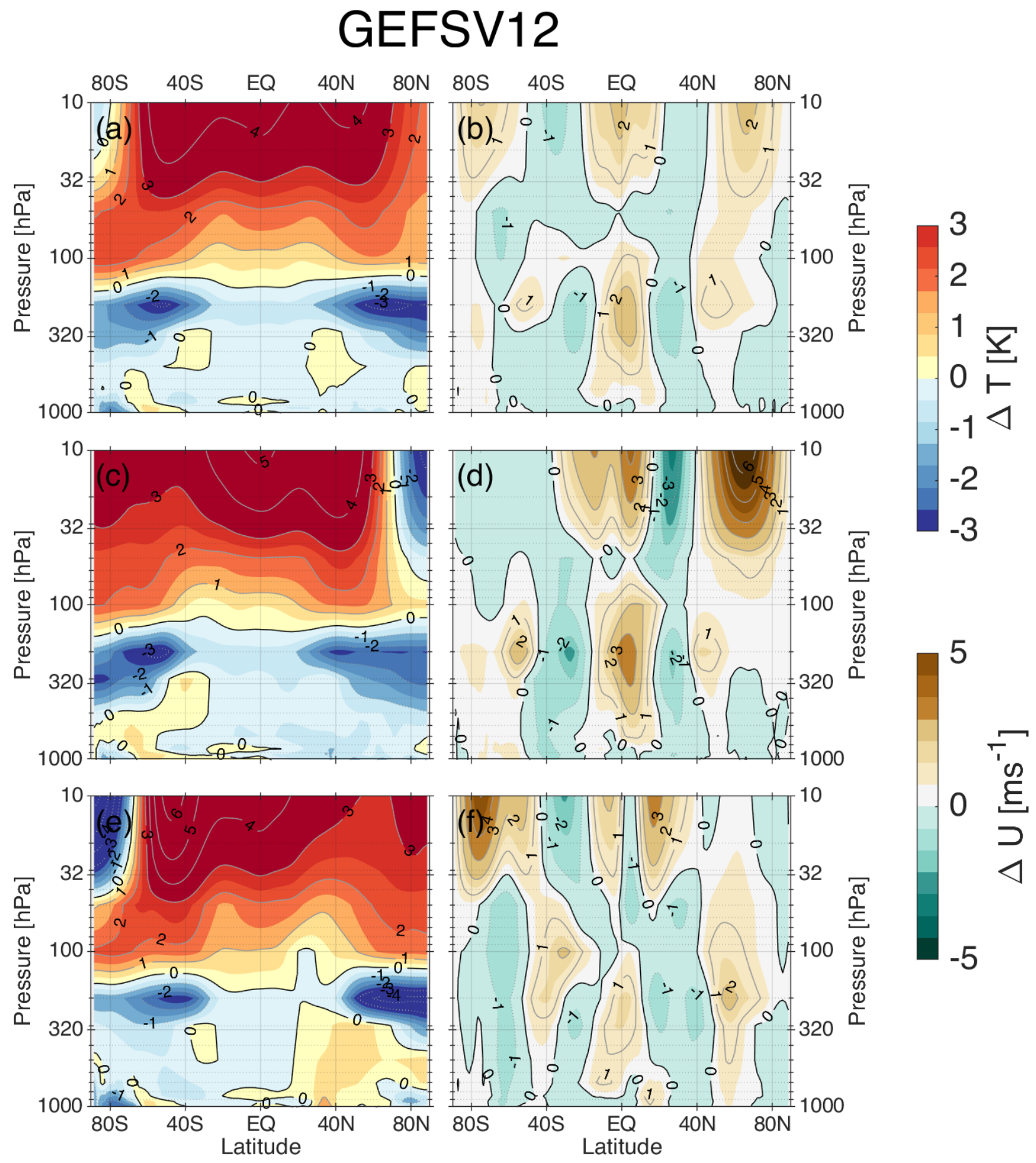

Figure S10. As in Figure S1, but for the GEFSv12 system. 


\section{GFDL-SPEAR *}
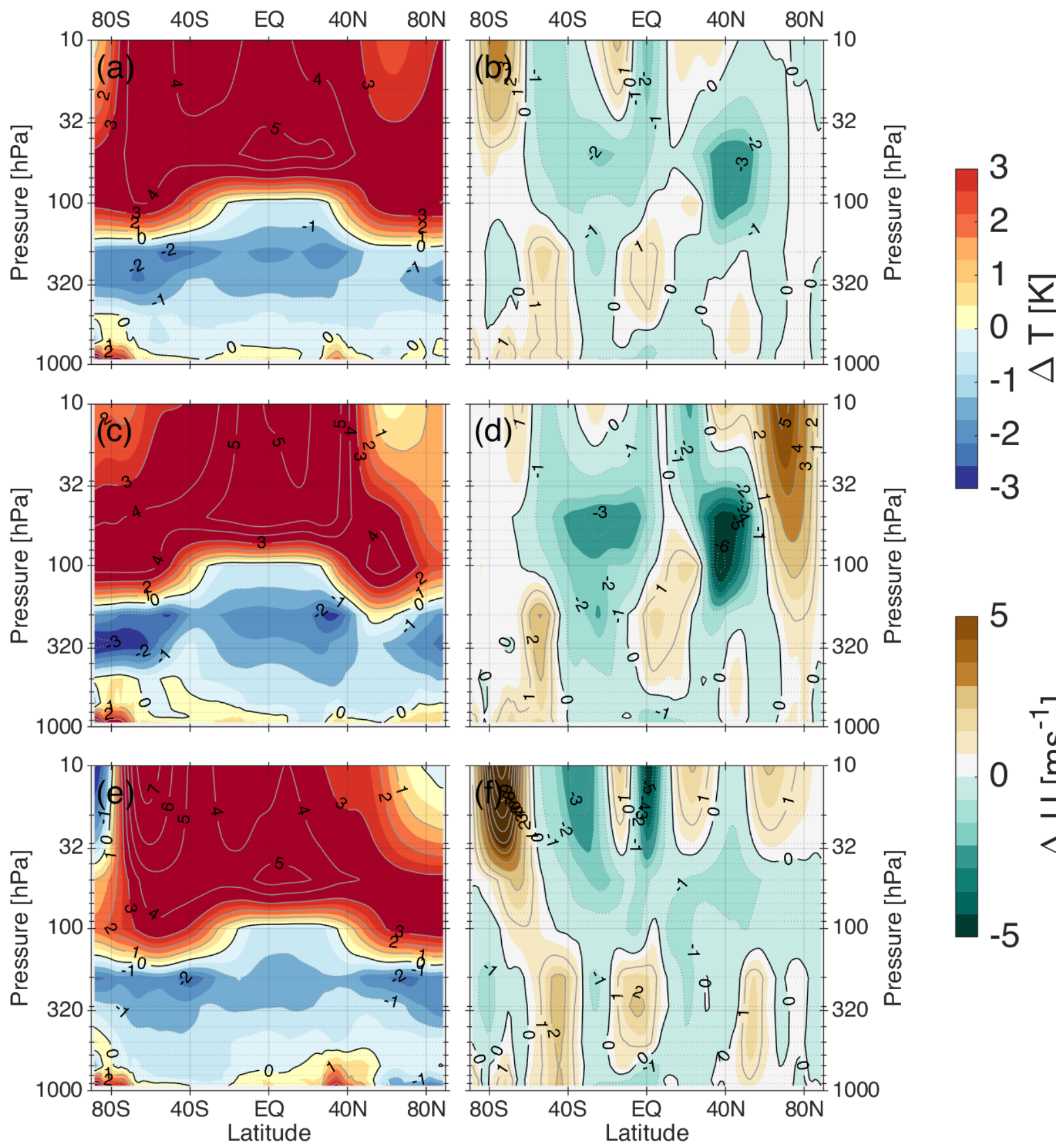

$-2$

$-3$

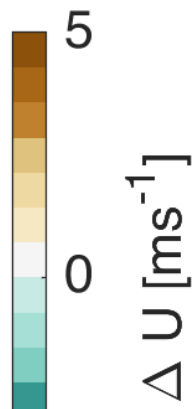

Figure S11. As in Figure S1, but for the GFDL-SPEAR system. 




Figure S12. As in Figure S1, but for the JMA system. 


\section{KMA}
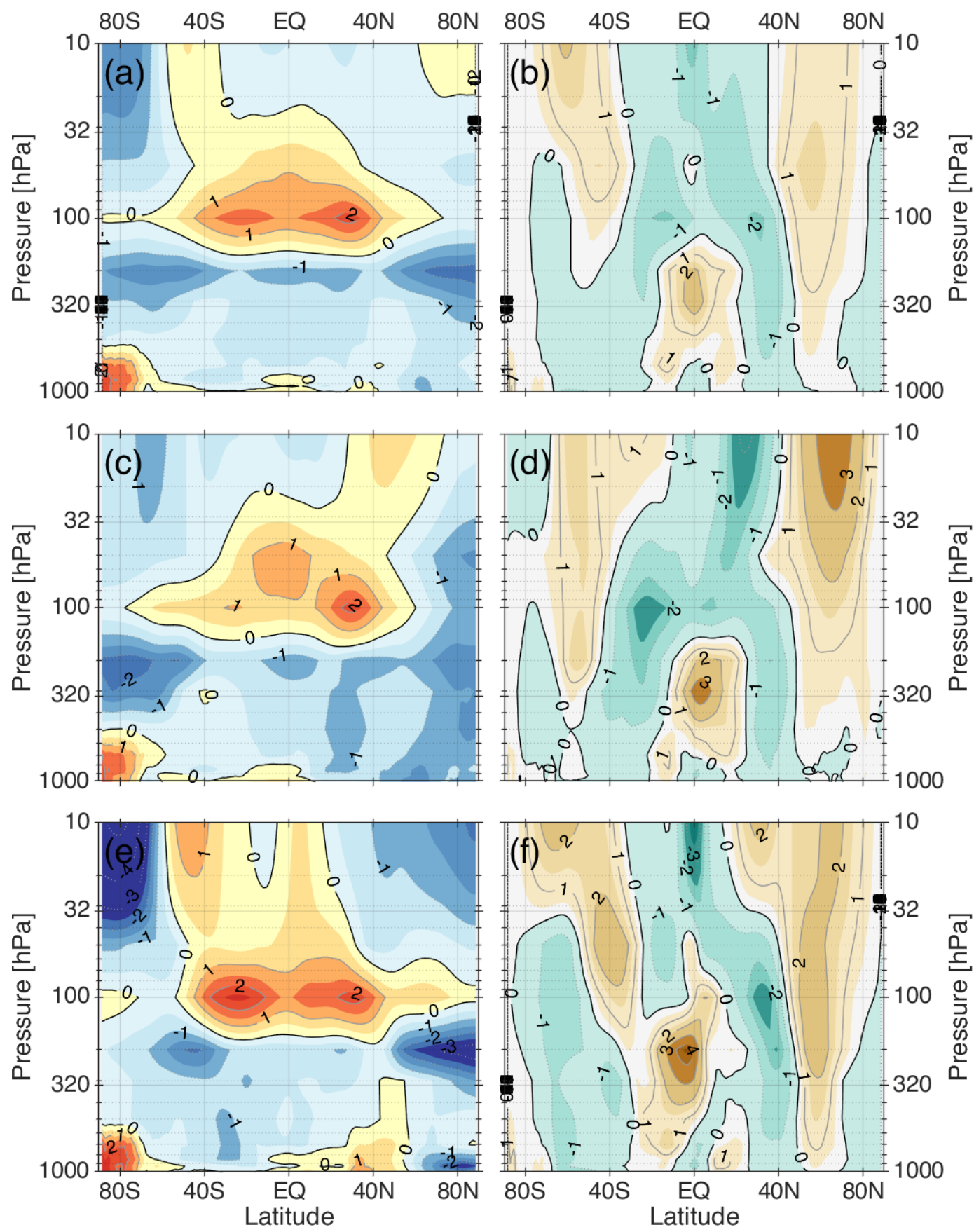

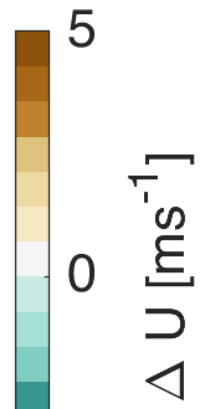

Figure S13. As in Figure S1, but for the KMA system. 


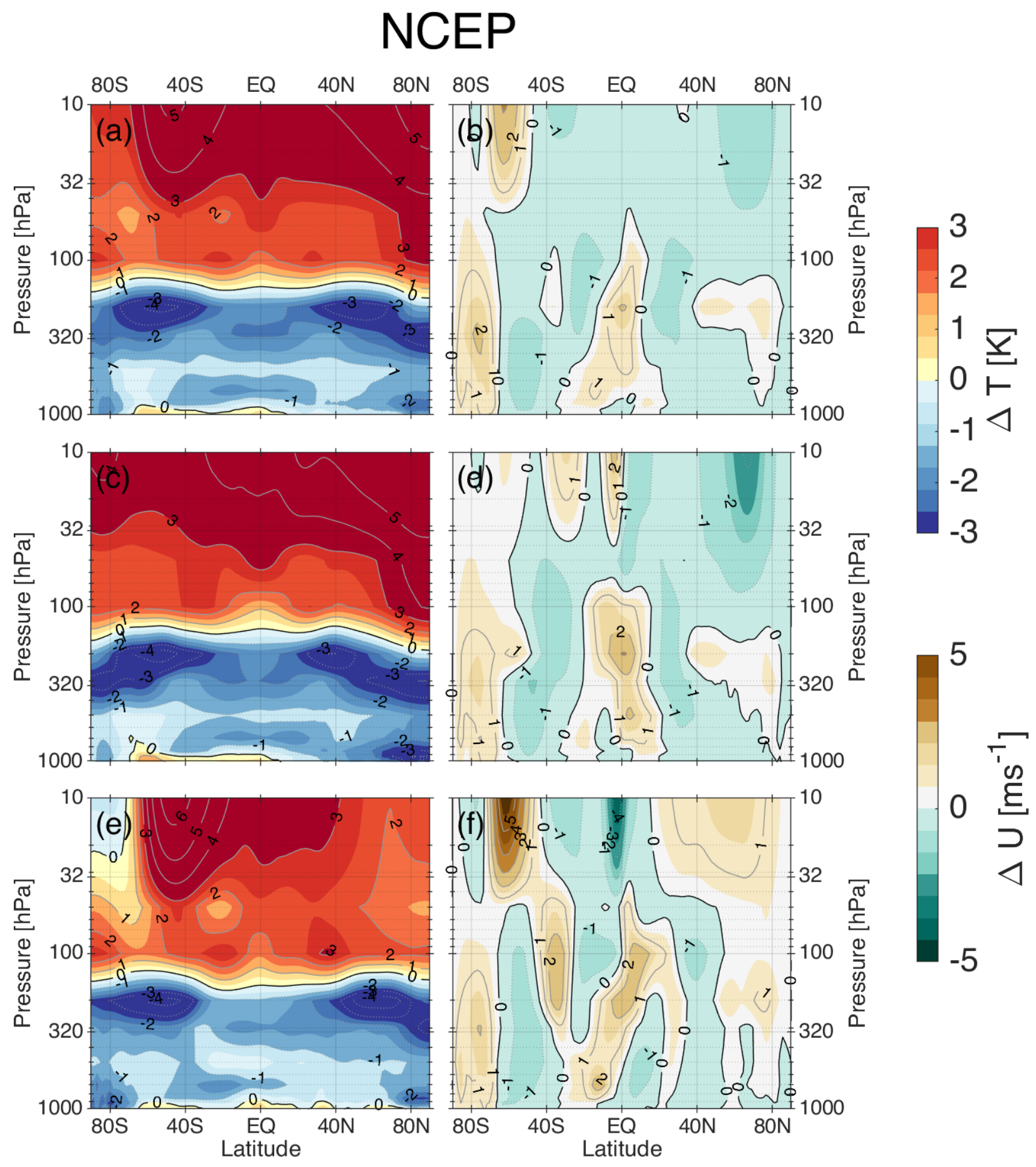

Figure S14. As in Figure S1, but for the NCEP system. 


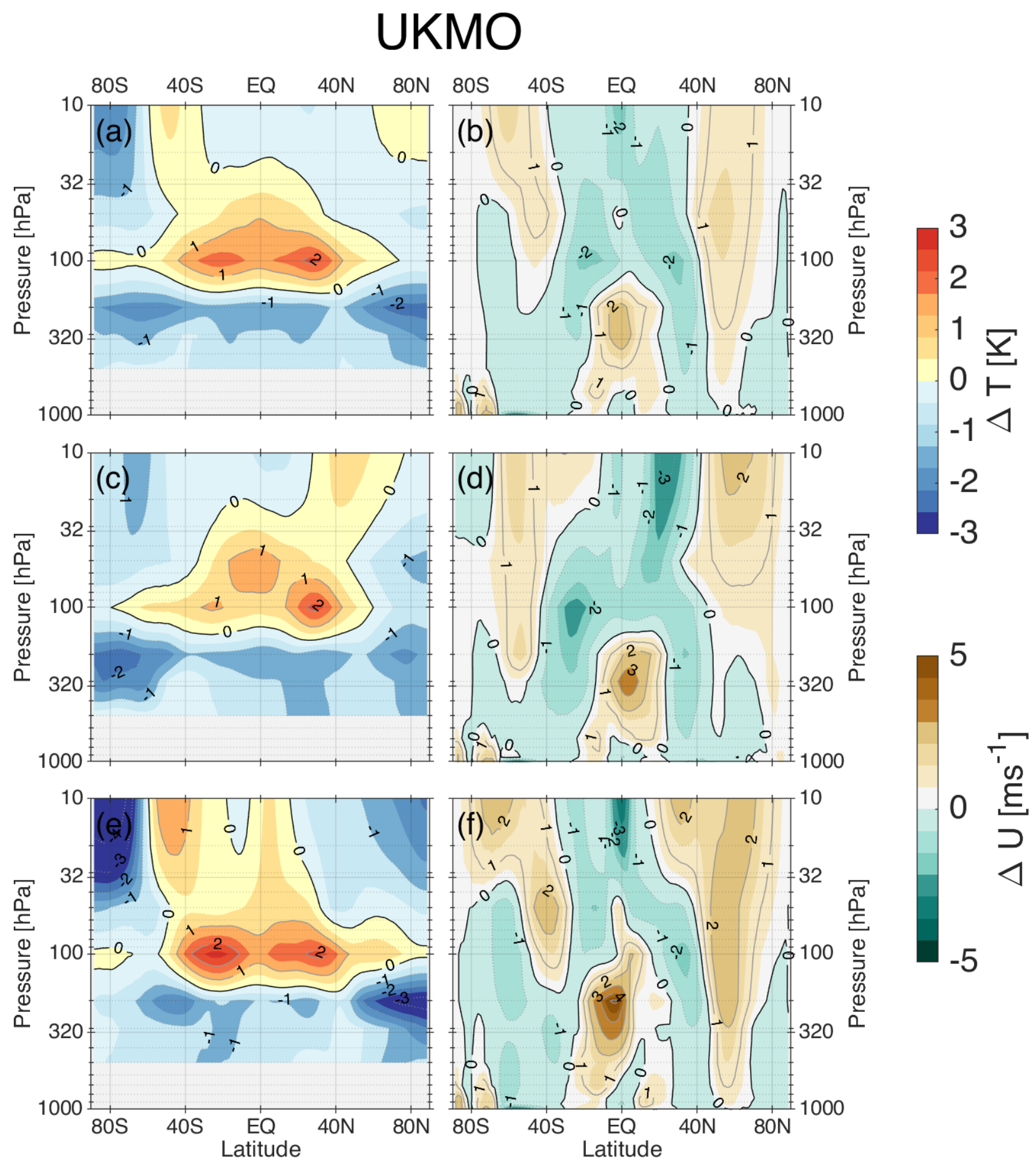

Figure S15. As in Figure S1, but for the UKMO system. 